\title{
Novel Therapy for Pseudocyst of Pinna - An Institutional Study
}

\author{
Debdulal Chakraborty, ${ }^{1}$ Chiranjib Das, ${ }^{1}$
}

\section{Introduction:}

\section{ABSTRACT}

Pseudocyst of pinna is a cystic swelling with collection of serous fluid between the auricular cartilage and perichondrium. Successful treatment of pseudocyst of pinna is challenging because of its high propensity for recurrence and cosmetic deformity. None of the treatment modalities described in literature gives fully satisfactory result. So a novel treatment modality is required which gives good cosmetic outcome with zero recurrence.

\section{Materials and Methods}

A prospective study was done in the Department of ENT and Head and Neck Surgery of a Government Medical College, West Bengal from April 2014 to March 2017. The effusion was aspirated aseptically with sterilized $10 \mathrm{ml}$ syringe with $18 \mathrm{G} I V$ needle. An equal amount of Inj. Dexamethasone and Inj. Gentamicin $80 \mathrm{mg}$ in 1:1 ratio mixed in a new $10 \mathrm{ml}$ syringe was injected into the swelling through the same prick point.

$\underline{\text { Result }}$

Most of the patients in this study were males between 31-40 years of age and labourer by profession. Maximum number of patients had swelling involving concha. Only one case of one month old infant had bilateral involvement. All patients were cured without any recurrence or disfigurement.

\section{Conclusion}

The results of present study points to the fact that aspiration and instillation of equal amount of Inj. Dexamethasone and Inj. Gentamicin works very good in treatment of pseudocyst of pinna. This therapy is minimally invasive, less painful, cost-effective and less cumbersome for the surgeon. It gives faster recovery, good cosmetic outcome and recurrence is prevented.

Keywords:

Pseudocyst; Pinna

$\mathrm{F}$ acial aesthetic is the composite result of normal individual facial structures, the pinna being one of them. Lesions affecting the pinna can lead to overt disfigurement and change the entire appeal of the face. Pseudocyst of pinna is a cystic swelling with collection of serous fluid between the auricular cartilage and perichondrium. ${ }^{1}$ Successful treatment of pseudocyst of pinna is challenging because of its high propensity for recurrence. Moreover, many a times the pinna becomes deformed permanently. Various treatments are described in the literature. However, none of them gives fully satisfactory result. ${ }^{2}$ So a novel treatment modality is required which maintains the shape of pinna as well as

1 - Department of ENT, BSMCH, Bankura

\section{Corresponding author:}

Dr Chiranjib Das

email: chirubata.das.87@gmail.com has zero recurrence.

\section{Materials and Methods}

A prospective study was done in the Department of ENT and Head and Neck Surgery of a Government Medical College, West Bengal. Forty two patients with pseudocysts of the pinna were enrolled in the study for a period of 3 years from April 2013 to March 2017 after they understood and accepted the procedure. The study was approved by the Institutional Ethical Committee. Pseudocysts of pinna were diagnosed on the basis of clinical presentation and characteristics of the aspirated fluid. Those patients who came very late with perichondrial abscess were excluded from the study. Thereafter the effusion was aspirated aseptically with sterilized $10 \mathrm{ml}$ syringe with $18 \mathrm{G}$ IV needle. Then the amount of fluid aspirated was noted and sent to 


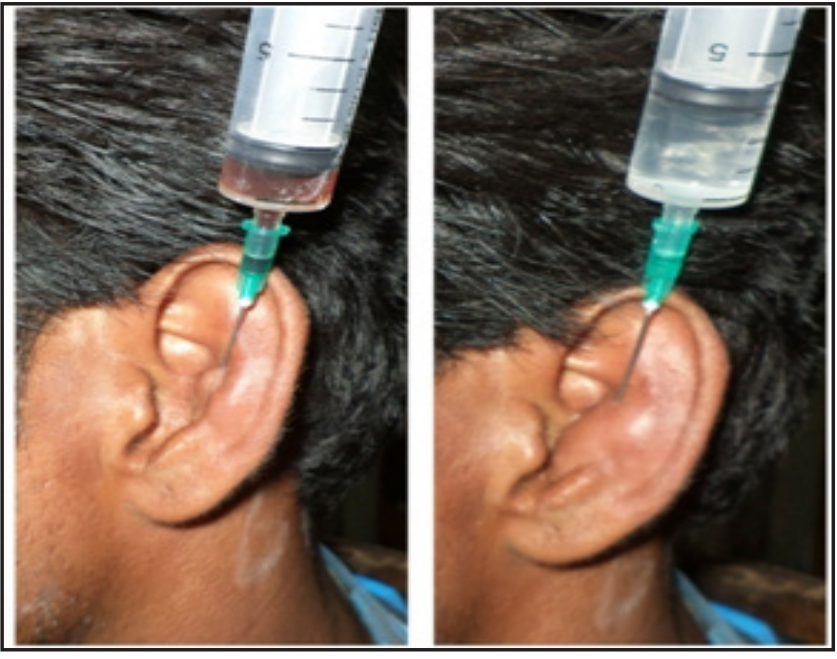

Fig. 1. Aspiration and injection in pseudocyst of concha

Department of Microbiology for culture and sensitivity test. An equal amount of Inj. Dexamethasone and Inj. Gentamicin $80 \mathrm{mg}$ in 1:1 ratio mixed in a new $10 \mathrm{ml}$ syringe was injected into the swelling through the same prick point (Figs. 1 and 2). Then light dressing was done with sterile gauze piece and adhesive tape. All these procedures were done in the OPD. The procedure was repeated every week (maximum 3 such) until there is remission of signs and symptoms pseudocyst and complete recovery to normal healthy pinna. Adjunctive

Table I: Age and sex distribution of patients

\begin{tabular}{|c|c|c|c|}
\hline $\begin{array}{c}\text { AGE GROUP IN } \\
\text { YEARS }\end{array}$ & MALE & FEMALE & TOTAL \\
\hline$<10$ & 1 & 1 & 2 \\
\hline $11-20$ & 1 & 1 & 2 \\
\hline $21-30$ & 6 & 1 & 7 \\
\hline $31-40$ & 16 & 1 & 17 \\
\hline $41-50$ & 10 & 0 & 10 \\
\hline $51-60$ & 3 & 0 & 3 \\
\hline$>60$ & 1 & 0 & 1 \\
\hline
\end{tabular}

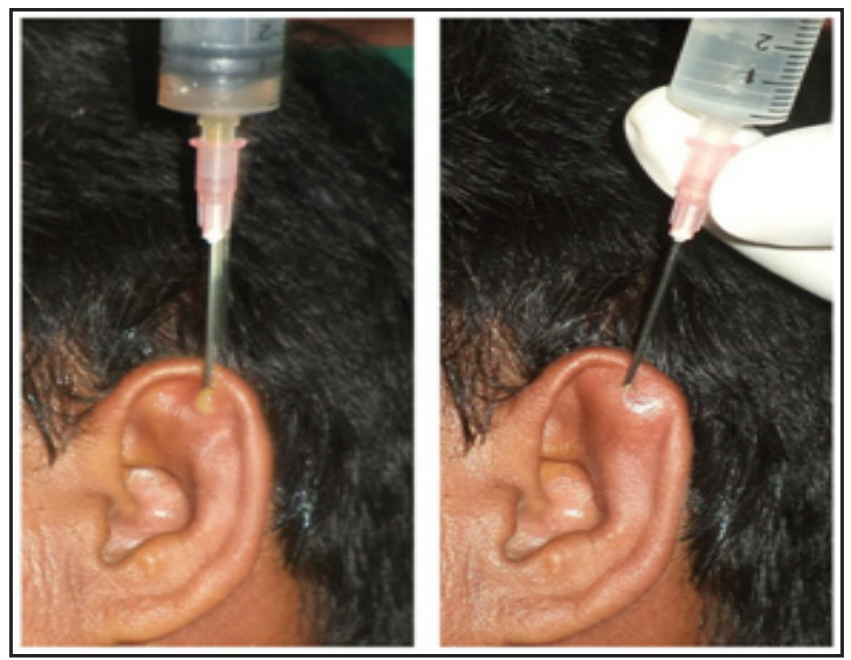

Fig. 2. Aspiration and injection in pseudocyst of scaphoid fossa

to this oral fluroquinolone antibiotic, Ciprofloxacin was given in adults and Azithromycin was chosen for children below 18 years of age. They were followed up every week up to 4 weeks, then at 2 months, 6 months and 1 year.

\section{Result}

Total number of patients enrolled in the study was forty two. Among them only four were females. Maximum numbers of patients (17) were in the age group of 3140 years comprising about $40.48 \%$ of study population (Table I). Most of them (28) were labourer by profession (Table II). Maximum numbers of patients (21) had swelling involving concha followed by concha and antihelix while minimum numbers of patients (3) had involvement of scaphoid and triangular fossa (Table III). Involvement of both right and left ears was seen, but left ear was involved more than right with 34 and 7 cases, respectively. Only one case of one month old infant had bilateral pseudocyst of pinna (Table IV).

The fluid aspirated was straw serum coloured in majority of patients (29) while few of them had serosanguinous fluid or blood mixed fluid (Table IV). Culture of the aspirated fluid from pseudocyst was sterile in maximum cases (28). Staphylococcus aureus was found in 10 patients and Pseudomonous aeruginosa was found in 4 patients (Table IV). The 
Table II: Distribution of patients according to profession

\begin{tabular}{|c|c|}
\hline PROFESSION & NUMBER OF PATIENTS \\
\hline Labourer & 28 \\
\hline Businessmen & 7 \\
\hline Servicemen & 3 \\
\hline Student & 2 \\
\hline None & 2 \\
\hline
\end{tabular}

size of the swelling varied from 1 to $3 \mathrm{~cm}$ in largest diameter. The volume of the fluid varied from 0.5 to 4 $\mathrm{ml}$. All patients tolerated the procedure well. 32 patients were completely cured with single procedure. Twelve patients needed two procedures and five patients needed three procedures. None of the patients had experienced any pain, fever, or oedema. The seroma disappeared without disfigurement. Further follow up showed no recurrences. We found that they were satisfied with the treatment since there were no heavy pressure dressings and was cosmetically acceptable.

\section{Discussion}

The first report of pseudocyst of pinna was by Hartmann in $1846 .{ }^{3}$ Males are commonly affected and the mean age of presentation is $35-40$ years. ${ }^{4}$ We found pseudocysts predominately in males and only four cases were seen in females. Young children are rarely affected as seen in our study and in other studies. ${ }^{5}$ Majority of the pseudocysts in the present study were involving concha. Supiyaphun and Decha ${ }^{5}$ also noted concha as the most common site of predilection while Engel ${ }^{1}$ and Cohen and Grossman ${ }^{6}$ in contrast cited the scaphoid fossa and triangular fossa of the antihelix as the main sites of predilection. The aetiology of this condition is unknown but at the same time many investigators believe that
Table III: Distribution of patients according to site of involvement

\begin{tabular}{|c|c|}
\hline SITE & NUMBER PATIENTS \\
\hline Concha & 21 \\
\hline Concha + Antihelix & 11 \\
\hline Scaphoid fossa & 7 \\
\hline $\begin{array}{c}\text { Triangular fossa }+ \\
\text { Scaphoid fossa }\end{array}$ & 3 \\
\hline
\end{tabular}

repeated minor injuries are responsible for the formation of pseudocysts, particularly in patients with pre-existing congenital intra-cartilaginous defects associated with lymphatic and vascular channels while some believe that the cause is cartilaginous degeneration caused by the release of chondrocyte lysosomal enzymes. ${ }^{5}$

Pseudocysts usually present unilaterally, but there are reports of bilateral presentation. ${ }^{6}$ Bilateral lesions are found in only $13 \%$ of the patients and are mainly reported in the paediatric age group. ${ }^{5} \mathrm{We}$ found one case of one month infant suffering from chondromalacia with bilateral involvement. Pseudocysts occur more commonly on the right side as reported by many authors but we found them more on the left side. Similar to our study, one study noted pseudocyst to occur more commonly on the left side. ${ }^{6}$ Usually these cysts are asymptomatic but occasionally, minor discomfort and mild inflammatory signs may be present. ${ }^{4}$ The differential diagnosis of this condition includes cellulitis, relapsing polychondritis, chondrodermatitis helicis, and subperichondrial hematoma secondary to trauma. ${ }^{4}$

Typically straw coloured serous fluid similar to olive oil is seen in the pseudocysts; however, serosanguineous fluid may sometimes be observed. ${ }^{4}$ The volume of the aspirates was reported to varies from 0.5 to $10 \mathrm{ml}^{4}$ and we found it between 0.5 and $4 \mathrm{ml}$. The size ranged from 1 to $5 \mathrm{~cm}$ in diameter ${ }^{4}$ and in our series, the size 
Table IV: Distribution of patients according to characteristics of pseudocyst pinna

CHARACTERISTICS

\begin{tabular}{|c|c|c|}
\hline \multirow{3}{*}{ Laterality } & Bilateral & 1 \\
\hline & Right & 7 \\
\hline & Left & 34 \\
\hline \multirow{3}{*}{ Colour of fluid } & Straw serum & 29 \\
\hline & Serosanguinous & 8 \\
\hline & Blood mixed & 5 \\
\hline \multirow{3}{*}{ Culture report } & Sterile & 28 \\
\hline & Staphylococcus aureus & 10 \\
\hline & Pseudomonous aeruginosa & 4 \\
\hline
\end{tabular}

ranged from $1 \mathrm{~cm}$ to $3 \mathrm{~cm}$. Various treatments are described in the literature such as needle aspiration, ${ }^{4}$ incision and drainage with subsequent contour pressure dressing, ${ }^{7}$ de-roofing procedure, ${ }^{8}$ insertion of a small drainage tube into the pseudocyst. ${ }^{9}$ Applying uniform positive pressure conforming to the contour of the pinna remains a challenge as does the maintenance of the pressure. Positive pressure application was tried in many ways, like, plaster of paris cast application, clipping, buttoning, and fashioned stainless steel wire. ${ }^{10}$ The application of positive pressure has its demerits ranging from patient noncompliance, discomfort, pain, and rarely ischemic necrosis of the skin. ${ }^{11}$ Patients tend to remove or manipulate the dressing to avoid social embarrassment. Eventually most of them would return with a recollection of seroma, leading to de-roofing operation as a second line of treatment. Ghanem et al have studied cases of recurrent pseudocyst of pinna after aspiration and pressure bandage and have stressed the need for an aggressive treatment. ${ }^{12}$ O'Donnell and Eliezri have also suggested that incision and drainage and removing a piece of cartilage with perichondrium would cure the condition rather simply aspirating the seroma. ${ }^{13}$ Many patients were reluctant for the deroofing operation at the first instance as it had to be carried out in the operation theatre. Most of them used to prefer for aspiration drainage only to return with a recollection.

It is not such that a cavity with collection should always be drained openly, for example, in breast abscesses, aspiration of the abscess is the initial treatment of choice recommended now. ${ }^{14}$ If a patient comes with cystic swelling of the pinna because of collection of hemorrhagic fluid and the aspiration shows no frank pus, no evidence of distraction of the cartilage, instead of incision and drainage a conservative approach can taken by simply aspirating the fluid inside and instilling equal amount of a mixture of Inj. Dexamethsone and Inj. Gentamicin. This local application of steroids reduces increased capillary permeability, cellular infiltration, and later responses like capillary proliferation, collagen deposition, fibrinolytic activity and ultimately scar formation. The cardinal signs of inflammation redness, heat, swelling, and pain are also suppressed. ${ }^{15}$ 
Gentamicin takes care of the infection due to recurrent trivial trauma sustained by the pinna. Pattanaik also reported same approach in cases of perichondritis and pinna haematoma with an excellent result. ${ }^{16}$ Patigaroo et al used the commonly used technique of simple aspiration followed by intralesional steroid injection followed by pressure dressing. ${ }^{17}$ In our study no pressure dressings were applied and no complications have been noticed. This method is a minimally invasive, simple and effective.

\section{Conclusion}

Successful treatment of pseudocyst of pinna is a challenge because of its high propensity for recurrence. All treatment modalities, described in literature have their own demerits. The results of present study points to the fact that aspiration and instillation of equal amount of Inj. Dexamethasone and Inj. Gentamicin works very good in treatment of pseudocyst of pinna. This therapy is minimally invasive, less painful, cost-effective and less cumbersome for the surgeon. It gives faster recovery, good cosmetic outcome and recurrence is prevented.

\section{References}

1. Engel D. Pseudocyst of the auricle in Chinese. Arch Otolaryngol. 1966; 83:197-202

2. Karthikeyan DA, Alalasundaram K. Steroid injection and negative pressure application in successful treatment of auricular seroma. Indian J Otol. 2016; 22:168-70

3. Hartmann A. Uber Cystenbildung in der Ohrenmuschel. Arch Ohren Nasen Kehlkopfheilkd. 1846; 15:156-66

4. Ramadass T, Ayyaswamy G. Pseudocyst of auricle etiopathogenesis, treatment update and literature review. Indian J Otolaryngol Head Neck Surg. 2006; 58:156-9

5. Supiyaphun P, Decha W. Auricular pseudocysts: A treatment with the Chulalongkorn University vacuum device. Otolaryngol Head Neck Surg. 2001; 124:213-6

6. Cohen PR, Grossman ME. Pseudocyst of the auricle: Case report and world literature review. Otolaryngol Head Neck Surg. 1990; 116:1202-4

7. Karabulut H, Acar B, Selcuk K. Treatment of the nontraumatic auricular pseudocyst with aspiration and intralesional steroid injection. New J Med. 2009; 26:117-9

8. Kanotra SP, Lateef M. Pseudocyst of pinna: A recurrence-free approach. Am J Otolaryngol. 2009; 30:73-9

9. Ramalingam R, Ramalingam KK. Pseudocyst of the auricle: A new method of treatment. Indian J Otolaryngol Head Neck Surg. 1998; 50:172-4

10. Purwar A, Shetty V, Khanna S, Gupta S. Pressure appliance to prevent the recurrence of auricular seroma: A new clinical trial. J Oral Biol Craniofac Res. 2013; 3:42-4

11. Salgado CJ, Hardy JE, Mardini S, Dockery JM, Matthews MS Treatment of auricular pseudocyst with aspiration and local pressure. J Plast Reconstr Aesthet Surg. 2006; 59:1450-2

12. Ghanem T, Rasamny JK, Park SS. Rethinking auricular trauma. Laryngoscope 2005; 115:1251-5

13. O'Donnell BP, Eliezri YD. The surgical treatment of traumatic hematoma of the auricle. Dermatol Surg. 1999; 25:803-5

14. Naeem M, Rahimnajjad MK, Rahimnajjad NA, Ahmed QS, Fazel PA, Owais M. Comparison of incision and drainage against needle aspiration for the treatment of breast abscess. Am Surg. 2012; 78 (11):1224-7

15. Tripathi KD. Essentials of Medical Pharmacology. 6th ed. New Delhi (India): Jaypee Publishers; 2008. pp.276-87

16. Pattanaik S. Effective, simple treatment for perichondritis and pinna haematoma. J Laryngol Otol. 2009; 123(11):1246-9

17. Patigaroo SA, Mehfooz N, Patigaroo FA, Kirmani MH, Waheed A, Bhat S. Clinical characteristics and comparative study of different modalities of treatment of pseudocyst pinna. Eur Arch Otorhinolaryngol. 2012; 269:1747-54. 